\title{
A DVCC-Based Mixed-Mode Biquadratic Circuit
}

\author{
Takao Tsukutani ${ }^{1}$ and Noboru Yabuki ${ }^{2}$ \\ 1. National Institute of Technology, Matsue College, Matsue 690-8518, Japan \\ 2. National Institute of Technology, Tsuyama College, Tsuyama 708-8509, Japan
}

\begin{abstract}
This paper introduces a mixed-mode biquadratic circuit employing DVCCs (differential voltage current conveyors) and grounded passive components. The biquadratic circuit can perform mixed-mode operation selecting the input and output terminals. And the circuit enables LP (low-pass), BP (band-pass), HP (high-pass), BS (band-stop) and AP (all-pass) transfer functions by suitably choosing the input terminals. The circuit parameters $\omega_{0}$ and $\mathrm{Q}$ can be tuned orthogonally through adjusting the passive components. The biquadratic circuit enjoys very low sensitivities with respect to the circuit components. The achievement example is given together with simulation results by PSPICE.
\end{abstract}

Key words: Analog circuits, mixed-mode operation, biquadratic characteristics, differential voltage current conveyors.

\section{Introduction}

High performance active circuits have received much attention. The circuit designs employing active devices such as OTAs (operational transconductance amplifiers), CCIIs (second generation current conveyors) and DVCCs, etc., have been reported in literature [1-8].

As a DVCC is a current controlled current source, the DVCC-based circuit is very suitable for high frequency operation. The DVCC is configured by grounding one y-terminal with plus polarity of DDCC (differential difference current conveyor) [5]. The configuration of plus current output DVCC is simpler than minus current output one like as a CCII [4]. These features are very attractive to circuit designers. The several current-mode and voltage-mode circuits using the DVCCs have been discussed previously [5-8].

A biquadratic circuit is a very useful second-order function block for realizing high-order circuit transfer functions. In the biquadratic circuit design, it is desirable that various circuit characteristics are realized without component matching conditions.

Corresponding author: Takao Tsukutani, Dr., research field: analog signal processing.
Additionally, it is required to set the circuit parameters $\omega_{0}, \mathrm{Q}$ and $\mathrm{H}$ orthogonally or independently. In applications to analogue signal processing, it may be desirable to synthesize mixed-mode biquadratic circuits with input current or voltage and output current or voltage. The mixed-mode biquadratic circuits using OTAs and grounded capacitors have already been reported in the past [1-3]. However, DVCC-based mixed-mode biquadratic circuit with the above-mentioned performances has not yet been studied sufficiently.

This paper introduces a mixed-mode biquadratic circuit employing five DVCCs and grounded passive components. The biquadratic circuit can perform the current-mode, voltage-mode, transadmittance-mode and transimpedance-mode operations selecting the input and output terminals. And the circuit enables LP (low-pass), BP (band-pass), HP (high-pass), BS (band-stop) and AP (all-pass) characteristics by suitably choosing the input terminals. The circuit parameters $\omega_{0}$ and $\mathrm{Q}$ can be tuned orthogonally through adjusting the circuit passive components. It is made clear from sensitivity analysis that the circuit enjoys very low sensitivities to the circuit components.

A biquadratic circuit using DVCCCs 
(current-controlled DVCCs) is also introduced. The DVCCC is a device utilized parasitic resistance at $\mathrm{x}$-terminal of the DVCC. The biquadratic circuit is constructed with the DVCCCs and grounded capacitors only, and the circuit characteristics can be tuned electronically by the bias currents of the DVCCCs.

The achievement example is given together with simulation results by PSPICE. The circuit configuration is very suitable for both bipolar and CMOS implementations.

\section{DVCC}

Fig. 1 shows the symbol for the DVCC. This shows dual current output DVCC.

The standard DVCC can be characterized by:

$$
V_{x}=V_{y 1}-V_{y 2}, \quad I_{z}= \pm I_{x}
$$

In Eq. (1), the sign " \pm " shows the polarity of the current output $\mathrm{I}_{\mathrm{z}}$.

Fig. 2 shows the DVCC [5] with MOS transistors. The DVCC is configured by grounding one y-terminal with plus polarity of the DDCC.

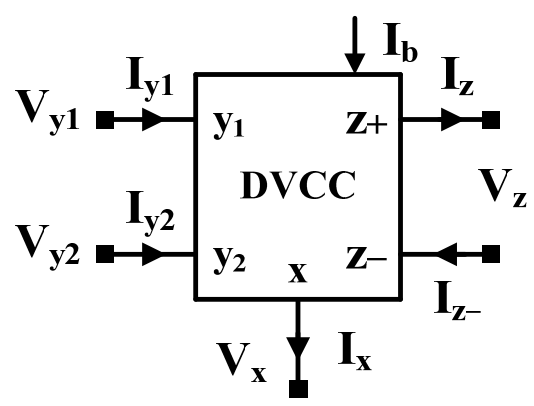

Fig. 1 Symbol for DVCC.

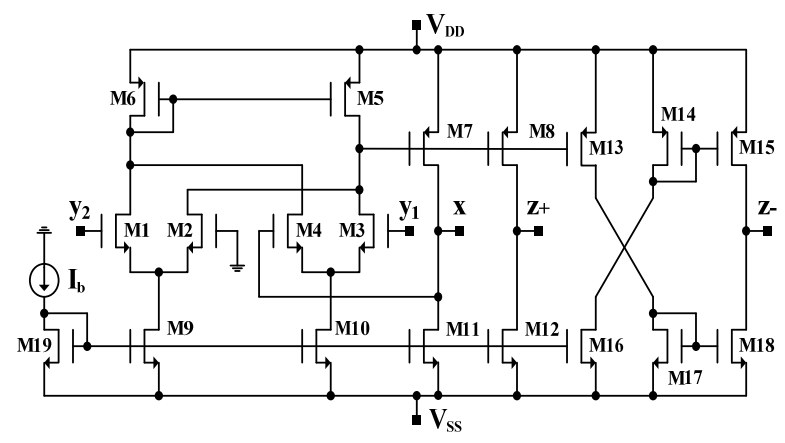

Fig. 2 DVCC with MOS transistors.

\section{Circuit Configuration and Analysis}

Fig. 3 shows the mixed-mode biquadratic circuit configuration. The circuit is constructed with four single current output DVCCs, one plus and minus current output DVCC and grounded passive components.

Routine analysis yields the voltage output $\mathrm{V}_{\text {out }}(\mathrm{s})$ and current output $\mathrm{I}_{\text {out }}(\mathrm{s})$ given by:

$$
\mathrm{V}_{\text {out }}(\mathrm{s})=\frac{\mathrm{N}_{\mathrm{v}}(\mathrm{s})}{\mathrm{D}(\mathrm{s})} \quad \text { (2) } \quad \mathrm{I}_{\text {out }}(\mathrm{s})=\frac{\mathrm{N}_{\mathrm{i}}(\mathrm{s})}{\mathrm{D}(\mathrm{s})}
$$

where,

$$
\begin{gathered}
\mathrm{N}_{\mathrm{v}}(\mathrm{s})=\mathrm{R}_{3}\left[\left\{\mathrm{I}_{\text {in } 3}(\mathrm{~s})+\frac{\mathrm{V}_{\text {in } 2}(\mathrm{~s})}{\mathrm{R}_{2}}\right\} \mathrm{s}^{2}-\frac{1}{\mathrm{C}_{2} \mathrm{R}_{2}}\left\{\mathrm{I}_{\text {in } 2}(\mathrm{~s})\right.\right. \\
\left.\left.+\frac{\mathrm{V}_{\text {in } 1}(\mathrm{~s})}{\mathrm{R}_{1}}-\frac{\mathrm{V}_{\text {in } 3}(\mathrm{~s})}{\mathrm{R}_{4}}\right\} \mathrm{~s}+\frac{1}{\mathrm{C}_{1} \mathrm{C}_{2} \mathrm{R}_{1} \mathrm{R}_{2}}\left\{\mathrm{I}_{\text {in1 } 1}(\mathrm{~s})+\frac{\mathrm{V}_{\text {in } 4}(\mathrm{~s})}{\mathrm{R}_{5}}\right\}\right] \\
\mathrm{N}_{\mathrm{i}}(\mathrm{s})=\frac{1}{\mathrm{R}_{3}} \mathrm{~N}_{\mathrm{v}}(\mathrm{s}) \\
\mathrm{D}(\mathrm{s})=\mathrm{s}^{2}+\frac{\mathrm{R}_{3}}{\mathrm{C}_{2} \mathrm{R}_{2} \mathrm{R}_{4}} \mathrm{~s}+\frac{\mathrm{R}_{3}}{\mathrm{C}_{1} \mathrm{C}_{2} \mathrm{R}_{1} \mathrm{R}_{2} \mathrm{R}_{5}}
\end{gathered}
$$

It is found from the equations above that the circuit can perform the mixed-mode operation by selecting the input and output terminals. And various circuit transfer functions can be realized choosing the input terminals suitably.

In current-mode operation, the way to realize the $\mathrm{LP}, \mathrm{BP}, \mathrm{HP}, \mathrm{BS}$ and AP transfer functions is as follows:

Current-mode operation $\left(\mathrm{V}_{\mathrm{in} 1}=\mathrm{V}_{\mathrm{in} 2}=\mathrm{V}_{\mathrm{in} 3}=\mathrm{V}_{\mathrm{in} 4}=\right.$ $0)$;

LP: $\mathrm{I}_{\text {in } 1}=\mathrm{I}_{\mathrm{in}}, \mathrm{I}_{\mathrm{in} 2}=\mathrm{I}_{\mathrm{in} 3}=0$

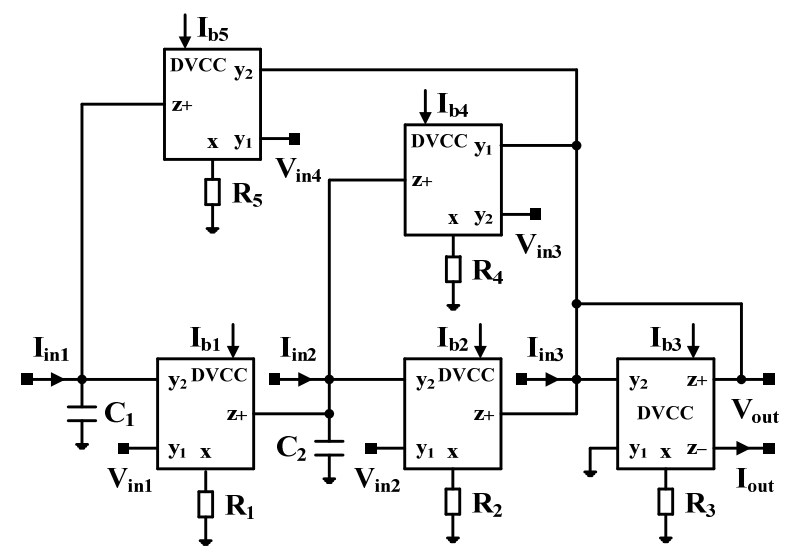

Fig. 3 Mixed-mode biquadratic circuit. 


$$
\begin{aligned}
& \mathrm{T}_{\mathrm{LP}}(\mathrm{s})=\frac{\mathrm{I}_{\text {out }}(\mathrm{s})}{\mathrm{I}_{\text {in }}(\mathrm{s})}=\frac{1 / \mathrm{C}_{1} \mathrm{C}_{2} \mathrm{R}_{1} \mathrm{R}_{2}}{\mathrm{D}(\mathrm{s})} \\
& \text { BP: } \mathrm{I}_{\mathrm{in} 2}=\mathrm{I}_{\mathrm{in}}, \mathrm{I}_{\mathrm{in} 1}=\mathrm{I}_{\mathrm{in} 3}=0 \\
& \mathrm{~T}_{\mathrm{BP}}(\mathrm{s})=\frac{\mathrm{I}_{\text {out }}(\mathrm{s})}{\mathrm{I}_{\text {in }}(\mathrm{s})}=-\frac{\left(1 / \mathrm{C}_{2} \mathrm{R}_{2}\right) \mathrm{s}}{\mathrm{D}(\mathrm{s})} \\
& \text { HP: } \mathrm{I}_{\mathrm{in} 3}=\mathrm{I}_{\mathrm{in}}, \mathrm{I}_{\mathrm{in} 1}=\mathrm{I}_{\mathrm{in} 2}=0 \\
& \mathrm{~T}_{\mathrm{HP}}(\mathrm{s})=\frac{\mathrm{I}_{\text {out }}(\mathrm{s})}{\mathrm{I}_{\mathrm{in}}(\mathrm{s})}=\frac{\mathrm{s}^{2}}{\mathrm{D}(\mathrm{s})} \\
& \mathrm{T}_{\mathrm{BS}}(\mathrm{s})=\frac{\mathrm{I}_{\text {out }}(\mathrm{s})}{\mathrm{I}_{\text {in }}(\mathrm{s})}=\frac{\mathrm{s}^{2}+1 / \mathrm{C}_{1} \mathrm{C}_{2} \mathrm{R}_{1} \mathrm{R}_{2}}{\mathrm{D}(\mathrm{s})} \\
& \mathrm{T}_{\mathrm{AP}}(\mathrm{s})=\frac{\mathrm{I}_{\text {out }}(\mathrm{s})}{\mathrm{I}_{\text {in }}(\mathrm{s})}=\frac{\mathrm{s}^{2}-\left(1 / \mathrm{C}_{2} \mathrm{R}_{2}\right) \mathrm{s}+1 / \mathrm{C}_{1} \mathrm{C}_{2} \mathrm{R}_{1} \mathrm{R}_{2}}{\mathrm{D}(\mathrm{s})}
\end{aligned}
$$

The circuit parameters $\omega_{0}$ and $\mathrm{Q}$ can be expressed as:

$$
\omega_{0}=\sqrt{\frac{\mathrm{R}_{3}}{\mathrm{C}_{1} \mathrm{C}_{2} \mathrm{R}_{1} \mathrm{R}_{2} \mathrm{R}_{5}}}, \quad \mathrm{Q}=\mathrm{R}_{4} \sqrt{\frac{\mathrm{C}_{2} \mathrm{R}_{2}}{\mathrm{C}_{1} \mathrm{R}_{1} \mathrm{R}_{3} \mathrm{R}_{5}}}
$$

The circuit parameters $\omega_{0}$ and $Q$ are set orthogonally by adjusting the circuit components.

The sensitivities with respect to circuit components (resistors and capacitors) are shown in Table 1. We can find from these values that the biquadratic circuit enjoys very low sensitivities to the circuit components. Additionally, it is noted that the sensitivities do not depend on the circuit component values.

In the following, we consider the voltage-mode biquadratic circuit. The circuit transfer functions in the voltage-mode operation are obtained by selecting the input terminals as follows:

Voltage-mode operation $\left(\mathrm{I}_{\mathrm{in} 1}=\mathrm{I}_{\mathrm{in} 2}=\mathrm{I}_{\mathrm{in} 3}=0\right)$

$$
\begin{aligned}
\text { LP: } V_{\text {in } 4}=V_{\text {in }}, V_{\text {in } 1}=V_{\text {in } 2}=V_{\text {in } 3}=0 \\
T_{L P}(s)=\frac{V_{\text {out }}(s)}{V_{\text {in }}(s)}=\frac{R_{3} / C_{1} C_{2} R_{1} R_{2} R_{5}}{D(s)}
\end{aligned}
$$

Table 1 Sensitivity to circuit components.

\begin{tabular}{lll}
\hline $\mathrm{x}$ & $\mathrm{S}_{\mathrm{x}}^{\omega_{0}}$ & $\mathrm{~S}_{\mathrm{x}}^{\mathrm{Q}}$ \\
\hline $\mathrm{R}_{1}$ & -0.5 & -0.5 \\
$\mathrm{R}_{2}$ & -0.5 & 0.5 \\
$\mathrm{R}_{3}$ & 0.5 & -0.5 \\
$\mathrm{R}_{4}$ & 0.0 & 1.0 \\
$\mathrm{R}_{5}$ & -0.5 & -0.5 \\
$\mathrm{C}_{1}$ & -0.5 & -0.5 \\
$\mathrm{C}_{2}$ & -0.5 & 0.5 \\
\hline
\end{tabular}

$$
\begin{gathered}
\text { BP: } V_{\text {in } 1}=V_{\text {in }}, V_{\text {in } 2}=V_{\text {in } 3}=V_{\text {in } 4}=0 \\
T_{B P}(s)=\frac{V_{\text {out }}(s)}{V_{\text {in }}(s)}=-\frac{\left(R_{3} / C_{2} R_{1} R_{2}\right) s}{D(s)} \\
\text { HP: } V_{\text {in } 2}=V_{\text {in }}, V_{\text {in } 1}=V_{\text {in } 3}=V_{\text {in } 4}=0 \\
T_{H P}(s)=\frac{V_{\text {out }}(s)}{V_{\text {in }}(s)}=\frac{R_{3}}{R_{2}} \frac{s^{2}}{D(s)} \\
\text { BS: } V_{\text {in } 2}=V_{\text {in } 4}=V_{\text {in }}, V_{\text {in } 1}=V_{\text {in } 3}=0 \\
T_{\text {BS }}(s)=\frac{V_{\text {out }}(s)}{V_{\text {in }}(s)}=\frac{R_{3}}{R_{2}} \frac{s^{2}+1 / C_{1} C_{2} R_{1} R_{5}}{D(s)} \\
\text { AP: } V_{\text {in } 1}=V_{\text {in } 2}=V_{\text {in } 4}=V_{\text {in }}, V_{\text {in } 3}=0 \\
T_{A P}(s)=\frac{V_{\text {out }}(s)}{V_{\text {in }}(s)}=\frac{R_{3}}{R_{2}} \frac{s^{2}-\left(1 / C_{2} R_{1}\right) s+1 / C_{1} C_{2} R_{1} R_{5}}{D(s)}
\end{gathered}
$$

The circuit parameters $\omega_{0}$ and $Q$ are same as the current-mode ones.

The transadmittance-mode and transimpedance-mode operations are performed selecting the input terminal $\mathrm{I}_{\text {in }}(\mathrm{s}) / \mathrm{V}_{\text {in }}(\mathrm{s})$ and output terminal $\mathrm{V}_{\text {out }}(\mathrm{s}) / \mathrm{I}_{\text {out }}(\mathrm{s})$, respectively. The circuit transfer functions are also obtained by the above-mentioned ways in these operation modes.

\section{DVCCC-Based Biquadatic Circuit}

In actuality, the parasitic resistance exists at the x-terminal as the non-ideality of the DVCC. And the value of the resistance varies by the bias current. The $\mathrm{x}$-terminal resistance $\mathrm{R}_{\mathrm{x}}$ is given by

$$
\mathrm{R}_{\mathrm{x}}=\mathrm{K}\left(\mu \mathrm{C}_{\mathrm{ox}} \frac{\mathrm{W}}{\mathrm{L}} \mathrm{I}_{\mathrm{b}}\right)^{-\frac{1}{2}}
$$

where $\mathrm{K}, \mu, \mathrm{C}_{\mathrm{ox}}, \mathrm{W} / \mathrm{L}$ and $\mathrm{I}_{\mathrm{b}}$ are the constant parameter, electron mobility, gate oxide capacitance per unit area, transistor aspect ratio and bias current, respectively. It is found from Eq. (18) that the $\mathrm{x}$-terminal resistance can be adjusted by the bias current electronically. The DVCC that utilized the $\mathrm{x}$-terminal resistance is called DVCCC.

Fig. 4 shows the biquadratic circuit configuration using the DVCCCs. This circuit is constructed with the DVCCCs and grounded capacitors only.

The voltage output $\mathrm{V}_{\text {out }}(\mathrm{s})$ and current output $\mathrm{I}_{\text {out }}(\mathrm{s})$ are given replacing the circuit resistance $R_{i}$ to the $\mathrm{x}$-terminal resistance $\mathrm{R}_{\mathrm{xi}}$ in Eqs. (4)-(17). Additionally, 


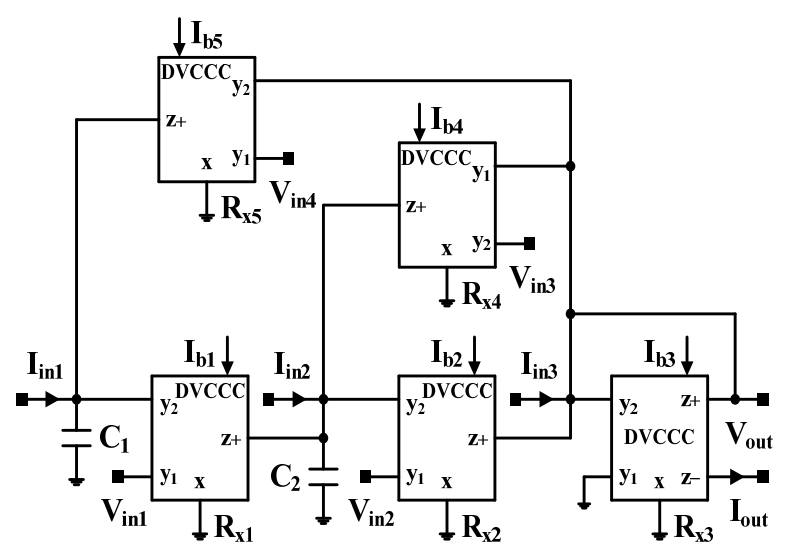

Fig. 4 DVCCC-based biquadratic circuit.

the circuit parameters $\omega_{0}$ and $\mathrm{Q}$ are induced by the same way. The circuit has electronic tuning capability for circuit characteristics adjusting the bias currents.

\section{Design Examples and Simulation Results}

As a design example, we consider a realization of the current-mode circuit characteristic with the cut-off frequency $f_{0}\left(=\omega_{0} / 2 \pi\right)=1 \mathrm{MHz}$, quality factor $\mathrm{Q}=1.0$ and gain constant $\mathrm{H}=1.0$. In this simulation, we have used a macro model of the DVCC shown in Fig. 2.

To realize the biquadratic characteristic above, we have determined that the resistors and capacitors would be $\mathrm{R}_{\mathrm{i}}(\mathrm{i}=1,2,3,4,5)=12 \mathrm{k} \Omega$ and $\mathrm{C}_{1}=\mathrm{C}_{2}=12$ $\mathrm{pF}$, respectively. Also, we have set the bias currents, supply voltages and input current at $\mathrm{I}_{\mathrm{bi}}(\mathrm{i}=1,2,3,4,5)$ $=10 \mu \mathrm{A}, \mathrm{V}_{\mathrm{DD}}=-\mathrm{V}_{\mathrm{SS}}=0.8 \mathrm{~V}$ and $\mathrm{I}_{\mathrm{in}}=10 \mu \mathrm{A}$.

Fig. 5 shows the circuit responses simulated with PSPICE. Fig. 5a shows the LP, BP, HP and BS responses. The all-pass response is shown in Fig. $5 b$. The marks show the simulation responses, meanwhile the solid lines are the ideal ones. The simulation responses are favorable enough over a wide frequency range. In the circuit, the power dissipation was 0.471 $\mathrm{mW}$.

In this simulation, the aspect ratios of the MOS transistors are listed in Table 2. And we have used the parameters obtained from MOSIS $0.5 \mu \mathrm{m}$ for other device parameters.

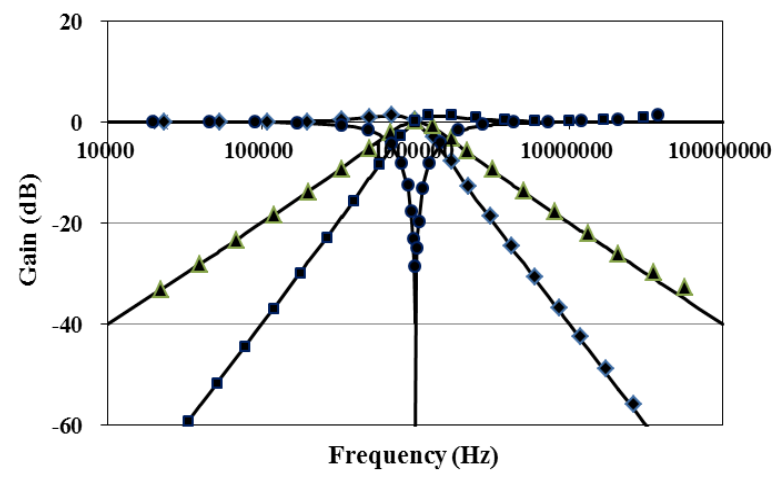

(a)

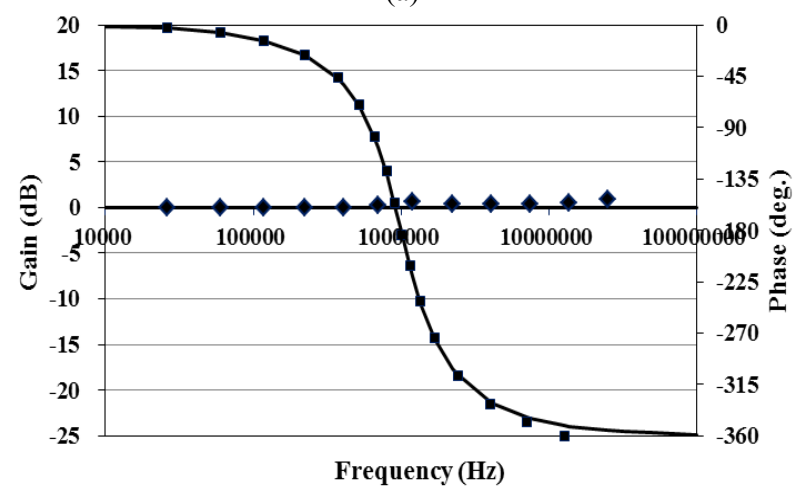

(b)

Fig. 5 Simulation responses.

Table 2 Aspect ratios of MOS transistors.

\begin{tabular}{ll}
\hline Transistors & W/L $(\mu \mathrm{m})$ \\
\hline M1-4 & $20 / 0.5$ \\
M5-8, M13-15 & $30 / 2$ \\
M9-12, M16-19 & $10 / 2$ \\
\hline
\end{tabular}

\section{Conclusions}

A mixed-mode biquadratic circuit employing DVCCs and grounded passive components has been proposed. We have demonstrated that the circuit can perform the mixed-mode operation by selecting the input and output terminals, and that the circuit enables LP, BP, HP, BS and AP transfer functions by suitably choosing the input terminals. Additionally, the circuit parameters $\omega_{0}$ and Q can be set orthogonally through adjusting the circuit components. It has been made clear that the biquadratic circuit enjoys very low sensitivities with respect to the circuit components.

The biquadratic circuit employing DVCCCs has also been presented. It has been shown that the circuit has tuning capability electronically for circuit 
characteristics by the bias currents.

The achievement example has been given together with simulation results by PSPICE. The simulation responses have been appropriate enough over a wide frequency range. The circuit configuration is very suitable for implementation on both bipolar and CMOS technologies.

The mixed-mode biquadratic circuit may be constructed with only plus current output DVCCs. The circuit configuration must be discussed in the future.

\section{References}

[1] Abuelma'atti, M. T., and Bentrcia, A. 2005. "A Novel Mixed-Mode OTA-C Universal Filter." International Journal of Electronics 92 (7): 375-83.

[2] Lee, C. N. 2010. "Multiple-mode OTA-C Universal Biquad Filters." Circuits, Systems, and Signal Processing 29: 263-74.

[3] Tsukutani, T., Fukuma, M., Sumi, Y., and Yabuki, N.
2016. "A Mixed-Mode Biquadratic Circuit Employing OTAs and Grounded Capacitors." In Proceedings of the ITC-CSCC 2016, pp.835-8.

[4] Horng, J. W. 2004. "High Input Impedance Voltage-Mode Universal Biquadratic Filters with Three Inputs Using Plus-Type CCIIs." International Journal of Electronics 91 (8): 465-75.

[5] Elwan, H. O., and Soliman, A. M. 1997. "Novel CMOS Differential Voltage Current Conveyor and Its Applications." IEE Proceedings on Circuits, Devices and Systems 144 (3): 195-200.

[6] Ibrahim, M. A., Minaei, S., and Kuntman, H. 2005. "A 22.5 MHz Current-Mode KHN-Biquad Using Differential Voltage Current Conveyor and Grounded Passive Elements." International Journal of Electronics and Communications 59: 311-8.

[7] Minaei, S., and Ibrahim, M. A. 2005. "General Configuration for Realizing Current-Mode First-Order All-Pass Filter Using DVCC." International Journal of Electronics 92 (6): 347-56.

[8] Tsukutani, T. 2007. "Novel Current-Mode Biquadratic Circuit Using Only Plus Type DO-DVCCs and Grounded Passive Components.” IBID 94 (12): 1137-46. 